\title{
The intrinsic apoptotic signaling pathway in gastric adenocarcinomas of Brazilian patients: Immunoexpression of the Bcl-2 family (Bcl-2, Bcl-x, Bak, Bax, Bad) determined by tissue microarray analysis
}

\author{
LUIS FERNANDO MESÍAS BARREZUETA, CELINA TIZUKO FUJIYAMA OSHIMA, \\ FLÁVIO OLIVEIRA LIMA, HENRIQUE DE OLIVEIRA COSTA, THIAGO SIMÃO GOMES, \\ RICARDO ARTIGIANI NETO and MARCELLO FABIANO DE FRANCO
}

Department of Pathology, Federal University of São Paulo (EPM_UNIFESP), CEP 04023-062, São Paulo, SP, Brazil

Received June 23, 2009; Accepted December 23, 2009

DOI: $10.3892 / \mathrm{mmr} 00000249$

\begin{abstract}
This study was undertaken to investigate the immunoexpression of Bcl-2 family proteins (Bcl-2, Bcl-x, $\mathrm{Bax}, \mathrm{Bak}$ and $\mathrm{Bad}$ ) and to evaluate the correlation between the immunoexpression of these proteins and that of cleaved caspase 3, Ki-67 and p53. A tissue microarray (TMA) paraffin block was constructed using gastric carcinoma tissue (test group) and adjacent normal gastric mucosa (control group) from 87 patients who had not previously undergone radiotherapy or chemotherapy. Sections from the TMA block (4 $\mu \mathrm{m}$ ) were subjected to immunohistochemistry for Bcl-2, Bcl-x, Bax, Bak, Bad, p53, Ki-67 and cleaved caspase-3. The slides were evaluated by the semi-quantitative method, and the scores obtained (intensity vs. percentage of staining) were correlated with one another and with the apoptotic index, cellular proliferation and data regarding patient survival. The studied proteins were present in the tumor tissue and in the normal gastric mucosa, but at different intensities and with differences in the number of positive cells. There was an association between tumor size and p53 expression, and intestinal type adenocarcinoma was positively correlated with the expression of Bax, Bad and Ki-67. The immunoexpression of Bcl-x, Bak, Bad, p53 and Ki-67 showed statistically significant differences between the tumor tissue and the adjacent normal gastric mucosa. There was an association between the expression of Bax, Bak and Bad in the normal gastric mucosa. No correlation between patient survival and the expression of these proteins was observed. Overexpression of
\end{abstract}

Correspondence to: Dr Luis Fernando Mesías Barrezueta, Department of Pathology, Federal University of São Paulo (EPM-UNIFESP), Rua Botucatu 740, CEP-04023-062 Vila Clementino, São Paulo, SP, Brazil

E-mail: luismesias@uol.com.br

Key words: gastric cancer, apoptosis, family Bcl-2, immunohistochemistry, prognosis the Bcl-x protein in the adenocarcinomas and the difference in $\mathrm{Bcl}-\mathrm{x}$ expression between the test and the control group may be related to the anti-apoptotic effect of this protein. The reduced expression of Bak and Bad and the increased expression of p53 and $\mathrm{Ki}-67$ in the adenocarcinomas demonstrate the imbalance between apoptosis and cellular proliferation, which results in uncontrolled tumor cell proliferation.

\section{Introduction}

Gastric cancer is the second leading cause of cancer-related death worldwide. It is among the most common types of malignancy in various parts of the world, including Japan and several regions of China and South America (World Health Organization, http://www.who.int/en). Statistical data reveal a global decline in the incidence of gastric cancer, mainly in developed countries, due to improvements in environmental sanitation, a reduction in salt in preserved foods, and increased early diagnosis and appropriate treatment (1). However, gastric cancer remains one of the most common tumors in Brazil, according to the population-based cancer registries of the country. In these registries, gastric cancer is ranked among the three most common types of cancer in men and among the five most common types in women (National Câncer Institute; Instituto Nacional do Câncer, http://www.inca.gov.br). In São Paulo, Brazil, gastric cancer ranks second as the leading cause of cancer-related death among men, and fourth among women (Fundação Oncocentro de São Paulo, http://www.fosp.saude. sp.gov.br/html/fr_dados.html).

Adenocarcinomas of the stomach can be classified into two major histological subtypes: intestinal and diffuse (2). The intestinal variant is thought to arise from gastric mucosal cells that have undergone intestinal metaplasia, and often occurs in the setting of chronic gastritis attributed to infection with Helicobacter pylori $(3,4)$. The development of cancer in an environment of atrophy and achlorhydria due to this infection is attributed to alterations in DNA caused by the interaction between chronic inflammation and alterations in the balance between cellular proliferation and apoptosis (5). This variant 
is the most differentiated type of gastric cancer. The diffuse variant is hypothesized to arise de novo from native gastric epithelial cells, and is poorly differentiated in general (6).

A variety of physiological death signals, as well as pathological cellular insults, trigger the genetically programmed pathway of apoptosis $(7,8)$. Apoptosis manifests in two major execution programs downstream of the death signal: the caspase pathway and organelle dysfunction, of which mitochondrial dysfunction is the best characterized (9-12). The intrinsic apoptotic pathway hinges on the balance between the activity of pro- and anti-apoptotic members of the Bcl-2 superfamily of proteins, which act to regulate the permeability of the mithochondrial membrane (13).

The ratio between these two subsets helps to determine, in part, the susceptibility of cells to a death signal (14). An additional characteristic of the members of this protein family is their frequent ability to form homodimers as well as heterodimers, suggesting a neutralizing competition between the proteins (15). A further characteristic of probable functional significance is their ability to become integral membrane proteins (16). High or low expression of these proteins by immunohistochemistry in pre-malignant lesions or in gastric adenocarcinomas suggests their involvement in gastric carcinogenesis $(17,18)$. Gastric cancer is generally poorly responsive to chemotherapy and radiotherapy, suggesting that these tumors are intrinsically resistant to the apoptosis-inducing effects of anticancer drugs and $\mathrm{X}$-irradiation. Overexpression of oncogenes, such as Bcl-2, suggests that these genes are potential molecular targets in anti-tumor therapy and the therapeutic modulation of apoptosis (19).

In this study, immunohistochemical methods were used to characterize the expression of several Bcl-2 family proteins in gastric adenocarcinomas.

\section{Materials and methods}

Patients and tissue specimens. Tissue samples were retrieved from the Department of Pathology of Sao Paulo Federal University, and consisted of 87 gastric adenocarcinoma tissue samples and 87 adjacent normal gastric mucosa samples collected between 2000 and 2005. The patient population comprised 51 men (58.6\%) and 36 women (41.4\%) aged 29-85 years (mean 62 years). Total gastrectomy had been performed in 40 patients $(46 \%)$ and partial gastrectomy in 47 patients (54\%). None of the patients had undergone radiotherapy or chemotherapy prior to surgery. Sixty-three patients (72.4\%) had lymph node involvement, while 24 (27.6\%) did not. Pathological stage was determined according to the TNM classification (20), and histological type according to the Lauren classification. Thirteen patients (14.9\%) were in clinical stage I, $15(17.2 \%)$ in stage II, $58(66.7 \%)$ in stage III and $1(1.2 \%)$ in stage IV. Ethical approval for the study was granted by the local ethics committee of the Federal University of São Paulo (Resolution no. 01647/06 of the National Health Council).

Tissue microarray block construction. Paraffin-embedded tumor and adjacent normal mucosal specimens fixed in formalin were sectioned $(4 \mu \mathrm{m})$ from each block and stained by $H \& E$. The slides were evaluated by expert pathologists to
Table I. Frequency of protein expression in gastric adenocarcinomas and normal gastric mucosa.

\begin{tabular}{lccr}
\hline Protein & $\begin{array}{c}\text { Total } \\
\mathrm{n}\end{array}$ & $\begin{array}{c}\text { Negative } \\
\mathrm{n}(\%)\end{array}$ & $\begin{array}{c}\text { Positive } \\
\mathrm{n}(\%)\end{array}$ \\
\hline Adenocarcinoma & & & \\
Bcl-2 & 84 & $81(95.2)$ & $3(4.8)$ \\
Bcl-x & 84 & $10(11.9)$ & $74(88.1)$ \\
Bax & 84 & $18(21.4)$ & $66(78.6)$ \\
Bak & 83 & $64(77.1)$ & $19(22.9)$ \\
Bad & 83 & $36(43.3)$ & $47(56.7)$ \\
p53 & 86 & $49(56.9)$ & $37(43.1)$ \\
Ki-67 & 84 & $19(22.6)$ & $65(77.4)$ \\
CC-3 & 84 & $17(20.2)$ & $67(79.8)$ \\
Normal mucosa & & & \\
Bcl-2 & 84 & $83(98.8)$ & $1(1.2)$ \\
Bcl-x & 84 & $21(25.0)$ & $63(75.0)$ \\
Bax & 84 & $25(29.7)$ & $59(70.3)$ \\
Bak & 83 & $21(25.3)$ & $62(74.7)$ \\
Bad & 83 & $8(9.6)$ & $75(90.4)$ \\
p53 & 86 & $84(97.6)$ & $2(2.4)$ \\
Ki-67 & 84 & $32(38.1)$ & $52(61.9)$ \\
CC-3 & 84 & $53(63.1)$ & $31(36.9)$ \\
\hline
\end{tabular}

CC-3, cleaved caspase-3.

confirm the diagnosis and re-evaluate the histopathological findings, and to select the sites for the removal of cylindrical cores used in the tissue microarray (TMA) construction. TMA blocks were constructed using Beecher Instruments ${ }^{\mathrm{TM}}$ (Silver Spring, MD, USA) according to the manufacturer's instructions as follows: i) the selected area in the respective paraffin block was marked; ii) a cylindrical core was created in the receptor block using the apparatus; iii) a 1-mm cylinder of tissue was extracted from the area of interest; iv) the cylindrical tissues obtained from the donating block were transferred to the core in the receptor block; v) new core positions were created in the receptor block, separated by fractions of $\mathrm{mm}$ such that a collection of tissue samples was created following the matrix arrangement; vi) the quality of the block was assessed before storing. To guarantee adhesion of the TMA block slices on the slides, an adhesive tape system (Instrumedics Inc., Hackensack, NJ, USA) was used.

Immunohistochemistry. Conventional $4-\mu \mathrm{m} \quad$ sections were obtained and mounted on slides pre-treated with 3-aminopropyltriethoxysilane (Sigma, St. Louis, MO, USA). Sections were then deparaffinized, hydrated and processed. Briefly, for antigen retrieval, slides were placed in $0.01 \mathrm{M}$ citrate-buffer ( $\mathrm{pH}$ 6.0) and heated in a steamer for $30 \mathrm{~min}$. Endogenous peroxidase was blocked by $10 \%$ hydrogen peroxide for $20 \mathrm{~min}$. The sections were incubated overnight with antibodies against Bcl-x (rabbit polyclonal, 1:500) (Dako, Denmark); Bcl-2 (100, mouse monoclonal, 1:100) (Santa Cruz Biotechnology Ltd., Santa Cruz, CA, USA); Bad (HI68, rabbit 
Table II. Relationship between clinicopathological parameters and immunohistochemical protein expression in the gastric adenocarcinomas.

\begin{tabular}{|c|c|c|c|c|c|c|c|c|}
\hline & $\mathrm{Bcl}-2$ & Bcl-x & Bax & $\mathrm{Bad}$ & Bak & p53 & Ki-67 & Cas 3 \\
\hline \multicolumn{9}{|l|}{ Age } \\
\hline$\leq 50$ & NS & NS & NS & NS & NS & NS & NS & NS \\
\hline$>50$ & NS & NS & NS & 0.021 & 0.026 & NS & NS & NS \\
\hline \multicolumn{9}{|l|}{ Gender } \\
\hline Male & NS & NS & NS & NS & NS & NS & NS & NS \\
\hline Female & NS & NS & NS & NS & NS & NS & NS & NS \\
\hline \multicolumn{9}{|c|}{ Tumor diameter } \\
\hline$\leq 3$ & NS & NS & NS & NS & NS & NS & NS & NS \\
\hline$>3$ & NS & NS & NS & NS & NS & 0.046 & NS & NS \\
\hline \multicolumn{9}{|c|}{ Inflammation } \\
\hline Moderate & NS & NS & NS & NS & NS & NS & 0.023 & NS \\
\hline Intense & NS & NS & NS & NS & NS & NS & NS & NS \\
\hline Mild & NS & NS & NS & NS & NS & NS & NS & NS \\
\hline \multicolumn{9}{|c|}{ Lauren classification } \\
\hline Intestinal & NS & NS & 0.001 & 0.001 & NS & NS & 0.002 & NS \\
\hline Diffuse & NS & NS & NS & NS & NS & NS & NS & NS \\
\hline \multicolumn{9}{|c|}{ Disease stage } \\
\hline Early & NS & NS & NS & NS & NS & NS & NS & NS \\
\hline Advanced & NS & NS & NS & NS & NS & NS & NS & NS \\
\hline \multicolumn{9}{|c|}{ Lymph node status } \\
\hline Positive & NS & NS & NS & NS & NS & NS & NS & NS \\
\hline Negative & NS & NS & NS & NS & NS & NS & NS & NS \\
\hline \multicolumn{9}{|l|}{ TNM stage } \\
\hline $\mathrm{T} 1$ & NS & NS & NS & NS & NS & NS & NS & NS \\
\hline $\mathrm{T} 2$ & NS & NS & NS & NS & NS & NS & NS & NS \\
\hline T3,T4 & NS & NS & NS & NS & NS & NS & NS & NS \\
\hline
\end{tabular}

NS, not significant.

polyclonal, 1:100) (Santa Cruz); Bax (N-20, rabbit polyclonal, 1:1500) (Santa Cruz); Bak (H-211, rabbit polyclonal, 1:200) (Santa Cruz); p53 (D07, mouse monoclonal, 1:100) (Dako); Ki-67 (MIB-1, mouse monoclonal, 1:100) (Dako); and anti-cleaved caspase 3 (AP1027, rabbit polyclonal, 1:1000) (Calbiochem, San Diego, CA, USA). The next morning, the sections were allowed to react with secondary biotinylating antibody and streptavidin-biotin-peroxidase (LSAB kit, Dako, USA) for $30 \mathrm{~min}$ each. Finally, the reaction was revealed using 3,3'-diaminobenzidine tetrahydrocloride (DAB) (Sigma) (0.07\% DAB in 0.05 M PBS buffer, pH 7.6, containing $0.01 \%$ hydrogen peroxide), counterstained with Harris hematoxylin and coverslipped with Entellan (Sigma). Negative and positive controls were run simultaneously. As a positive control, histological slides previously determined to be positive for the markers studied were used. Slides stained omitting the primary antibody were used as negative controls.

A cytoplasmic expression pattern for Bcl-x, Bcl-2, Bax, Bad, Bak and cleaved caspase-3 (CC-3) was observed, while a nuclear expression pattern was seen for p53 and Ki-67. These patterns were analyzed according to distribution and intensity criteria. A numerical scoring system with two categories was used to assess protein expression (21). In category A, the number of immunoreactive cells was classified as 0 or negative (no immunoreactive cells or $<10 \%$ immunoreactivity), 1 (10 to $<25 \%), 2$ (25 to $<50 \%)$ and 3 (>50\% immunoreactivity). In category $\mathrm{B}$, the intensity of immunostaining was classified as 0 or negative, 1 (no or weak immunostaining), 2 (moderate) and 3 (strong). The values for categories A and B were multiplied, resulting in an immunoreactive score ranging from 0 to 9, with 0-3 considered negative and 4-9 positive. To evaluate the expression of CC-3 and Ki-67 protein, Imagelab ${ }^{\mathrm{TM}}$ software (Diracom, SP, Brazil) was used.

Cells were counted with an Olympus ${ }^{\mathrm{TM}}$ BX-40 Trinocular microscope. In fields showing a more intense reaction ('hot-spots'), 200 cells were counted and the percentage of immunostained cells was analyzed (22). Representative areas of gastric adenocarcinoma tissue and adjacent normal gastric mucosa were captured using a Sony ${ }^{\mathrm{TM}}$ CCD camera under x400 magnification. 
A

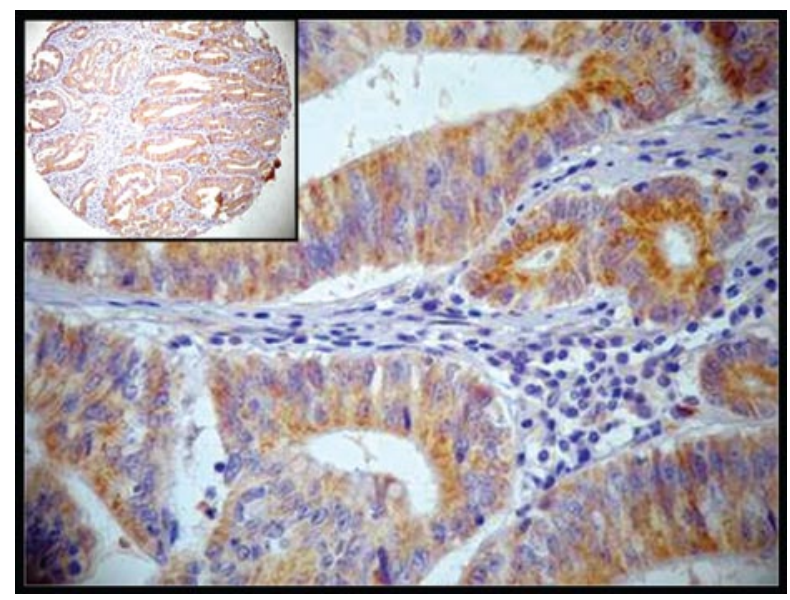

C

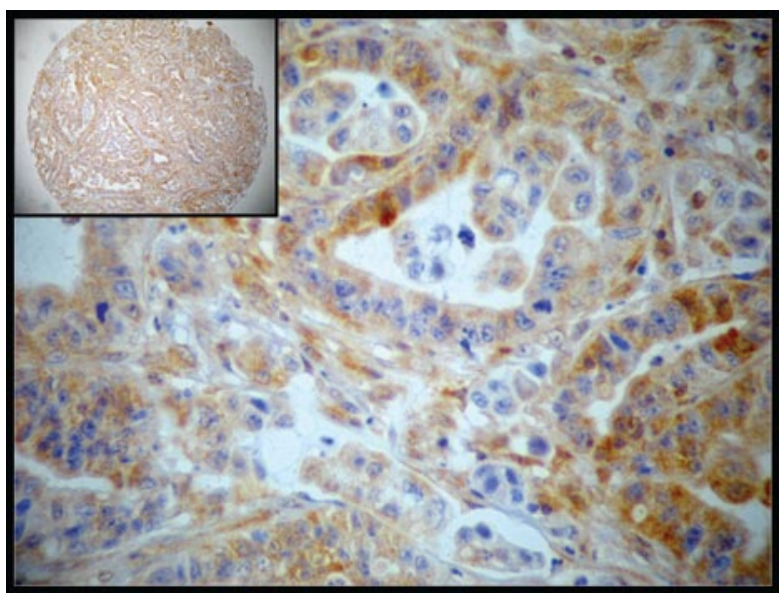

E

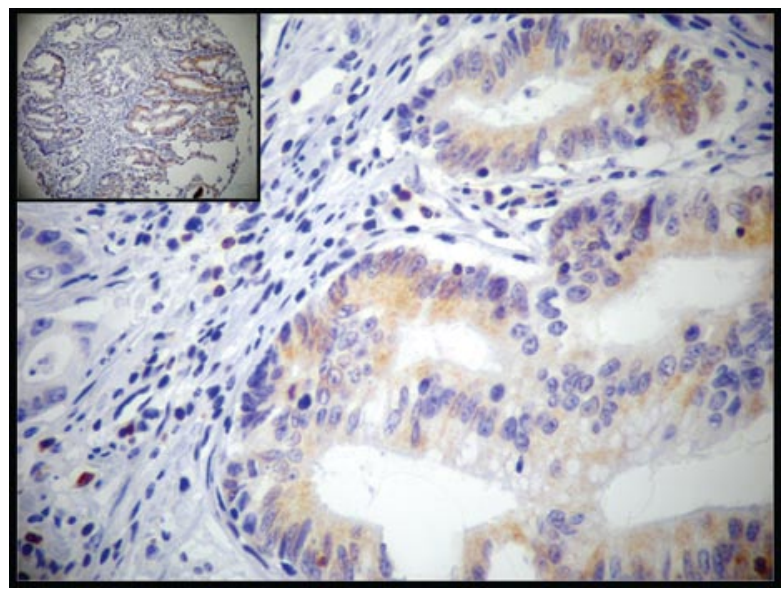

G

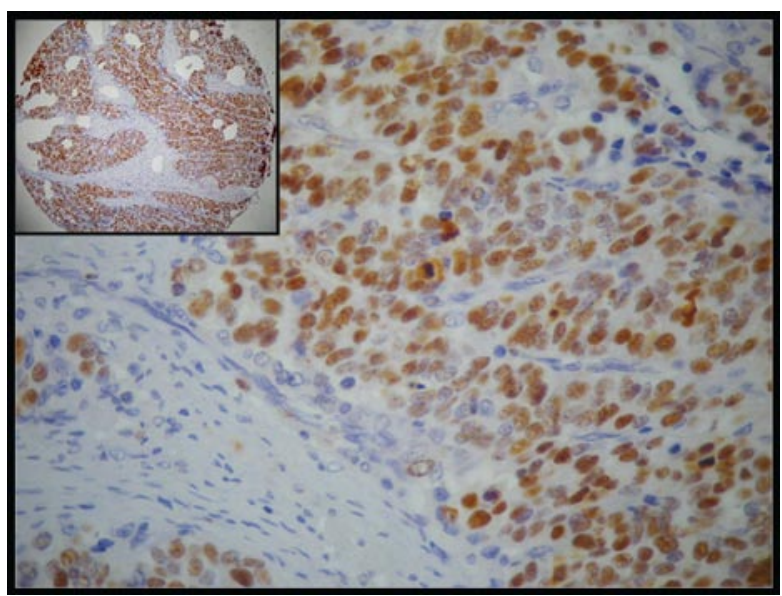

B

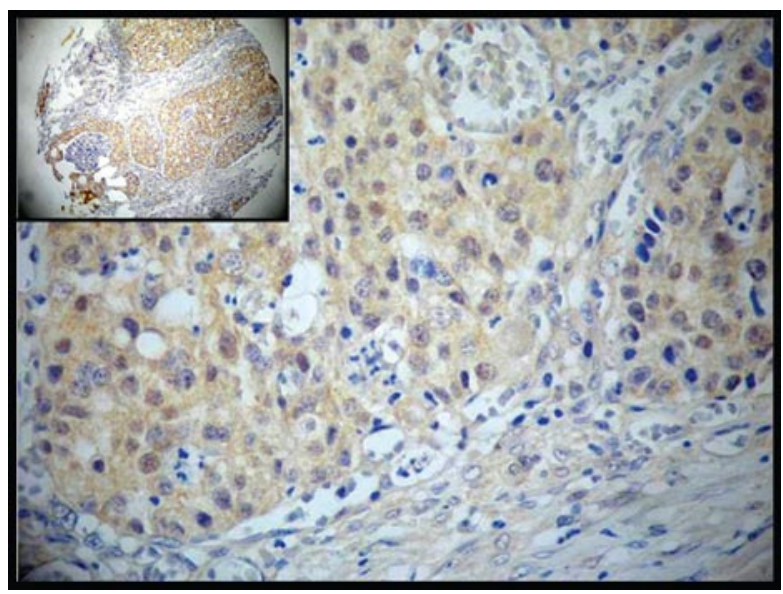

D

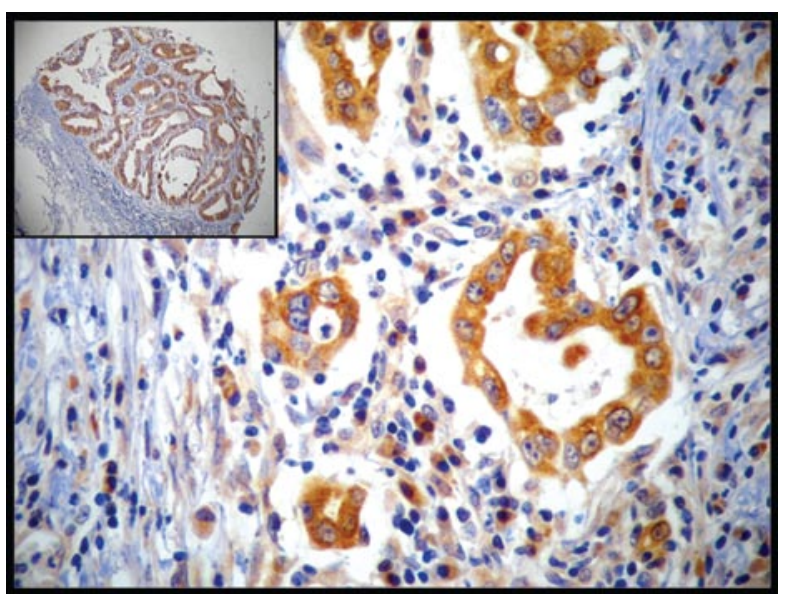

F

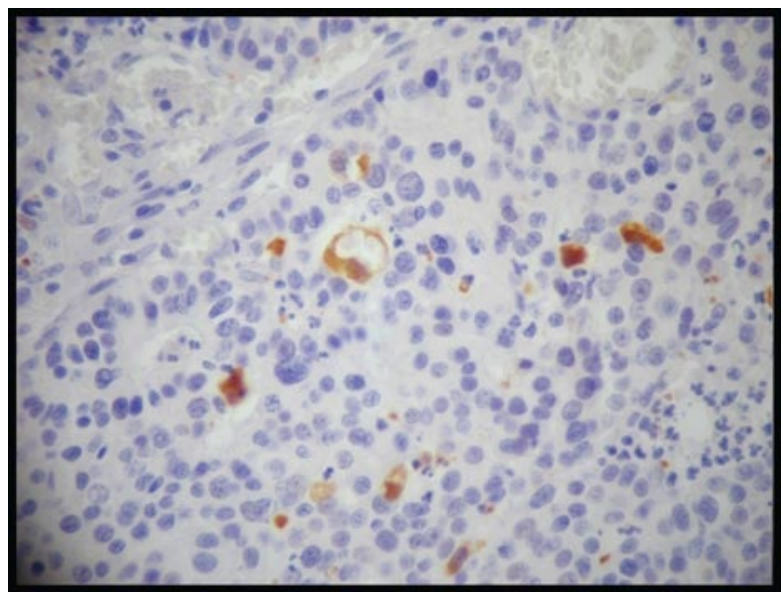

H

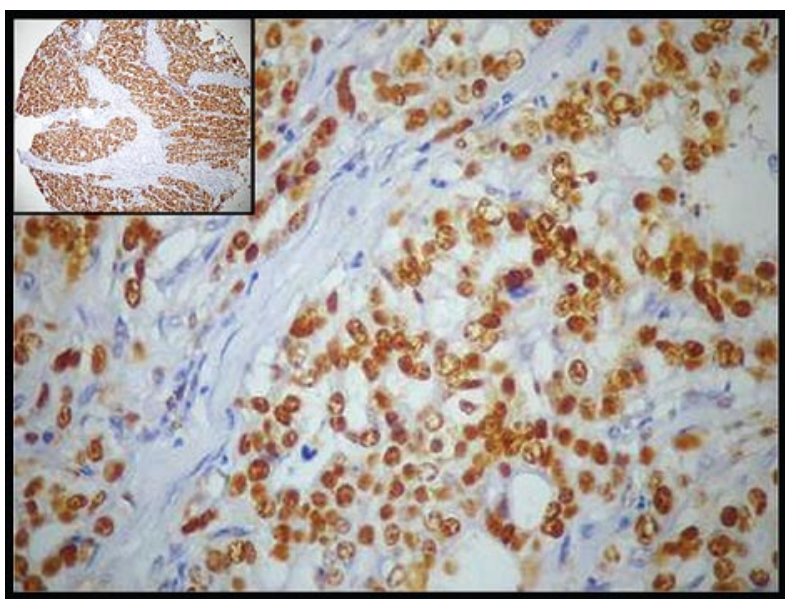

Figure 1. Immunohistochemical analysis of gastric adenocarcinoma tissue samples. A cytoplasmic expression pattern for Bak (A), Bad (B), Bax (C), Bcl-x (D), Bcl-2 (E) and cleaved caspase-3 (F), and a nuclear expression pattern for p53 (G) and Ki-67 (H), was observed. 
Statistical analysis. The relationships between the expression of Bcl-x, Bcl-2, Bax, Bad, Bak, p53, Ki-67 and CC-3 and the clinicopathological findings were evaluated using the $\chi^{2}$ test. Kaplan-Meier survival curves were constructed to assess whether the levels of Bcl-xl, Bcl-2, Bax, Bak, Bad, p53, Ki-67 and CC-3 had any effect on the overall survival of patients with gastric cancer. The correlation between the apoptotic index and cellular proliferation was evaluated using Pearson's test. A p-value $<0.05$ was considered statistically significant. Statistical analyses were performed with SPSS 15.0 for Windows.

\section{Results}

The frequency of protein expression in the gastric adenocarcinomas and adjacent normal gastric mucosa is shown in Table I. Table II shows the correlation between the clinicopathological parameters and expression of the proteins Bcl-2, Bcl-x, Bax, Bad, Bak, p53, Ki-67 and CC-3.

In the adenocarcinoma tissue, a correlation was demonstrated between Bad and Bax $(p=0.047)$ and between Bak and $\operatorname{Bad}(\mathrm{p}<0.001)$. Bcl-x was correlated with $\mathrm{Bad}(\mathrm{p}<0.001)$ and Bak $(\mathrm{p}<0.001)$. There was also a correlation between Ki-67 and Bcl-x (p=0.031), Bax (p=0.002), Bad ( $\mathrm{p}=0.045), \mathrm{p} 53$ $(\mathrm{p}=0.001)$ and $\mathrm{CC}-3(\mathrm{p}=0.037)$, and between Bad and CC-3 $(\mathrm{p}=0.020)$. Overexpression of Bcl-x, p53, Ki-67 and CC-3 and reduced expression of Bak and Bad in the tumor cells were observed.

Positive cytoplasmic expression of Bak (A), Bad (B), Bax (C), Bcl-x (D), Bcl-2 (E) and CC-3 (F) was observed, with a cytoplasmic expression pattern, while Ki-67 (G) and p53 (H) had a nuclear expression pattern (Fig. 1).

\section{Discussion}

The number of cells in normal tissue is carefully regulated through a balance between cell proliferation and apoptosis. An imbalance between these processes can result in the formation of cancer. Apoptosis is one of the key processes regulating cell number. Known intracellular mediators of apoptosis include pro- and anti-apoptotic members of the Bcl-2 family. Apoptosis is beneficial if it occurs as a compensatory response to cellular proliferation or as a mode of eliminating irreversibly damaged cells. In an attempt to understand gastric carcinogenesis, several studies have investigated anomalous expression of Bcl-2 in normal gastric mucosa and in pre-neoplastic lesions. The expression of this protein was increased in intestinal metaplasia compared to low and high grade dysplasias (23), and in dysplasias compared to adenocarcinomas (23). Among gastric carcinomas, $\mathrm{Bcl}-2$ expression was more frequent in the early than in the advanced stages of the disease (24), and was more frequently expressed in the intestinal compared with the diffuse type (25). These observations suggest the importance of Bcl-2 in gastric carcinogenesis, especially during its early stages.

In this study, the expression of Bcl-2 was noted in 3 $(4.8 \%)$ of the adenocarcinomas and in 1 (1.2\%) of the adjacent mucosal specimens. No differences were found in the expression of this protein in tumor tissue compared to normal mucosa.
Immunoexpression of Bcl-x was examined in normal gastric tissue and was present in various mucosal cells, including foveolar, parietal and chief cells (26). Increased expression was observed in $88.1 \%$ of the adenocarcinomas, compared to $75 \%$ of the normal mucosal specimens. The results of this analysis were similar to those of a previous study by Krajewska et al, which found Bcl-x immunoexpression in $88 \%$ of gastric adenocarcinomas (27). Several observations support the existence of a molecular connection and interface between cell death and cell cycle regulation. In addition to its central role in controlling cell death, studies have associated Bcl-2 with cell cycle progression. Due to its nuclear membrane localization, Bcl-2 may interfere with the nuclear transport of critical $\mathrm{S}$ phase progression factors, as has been shown for Cdc2 and Cdk2 (28). Schmitt et al suggested that Bcl-xl protein in human cancer modulates the cellular response to DNA damage by regulating the permeability of the mitochondrial membrane in the mechanism of apoptosis and by stabilizing the DNA damage checkpoint at the G2/M phase of the cell cycle, as well as by inhibiting cyclin-dependent kinase 1, thus preventing the apoptosis of cells with damaged DNA (29). Bcl-xl was also found to slow the apoptotic effect of chemotherapy on tumor cells. Increased expression of Bak sensitizes tumor cells to low doses of 5-FU and cisplatin, which are often used in the treatment of gastric cancer.

An association has been demonstrated between the Bcl-xl and the Bak and Bad proteins in adenocarcinomas. This association was described by Holinger et al (30) and Hinds et al (31), who suggested that Bak and Bad form heterodimers with the anti-apoptotic protein $\mathrm{Bcl}-\mathrm{xl}$, and that therefore any conformational change blocks the heterodimerization of Bak with Bcl-xl and inhibits the apoptotic effect of Bak. This observation suggests that Bak enhances apoptosis by binding to Bcl-xl and inhibiting its anti-apoptotic effect. In our study, increased expression of Bak and Bad was observed in the adjacent mucosa, while low expression of Bak and Bad was found in the adenocarcinomas. Krajewska et al found similar expression of Bcl-xl and Bak in colon cancer (32).

Reduced expression of the Bax protein has been shown to be a negative prognostic factor in patients with cancer of the breast, ovary, colon, esophagus and pancreas, and the loss of Bax expression in acute lymphoblastic leukemia in children is associated with resistance to chemotherapy and inappropriate activation of the caspase cascade (33). In this study, positive expression of Bax was observed in $78.6 \%$ of the adenocarcinomas and $70.3 \%$ of the normal mucosal specimens, which was without significant difference. However, in the two tissues there was a difference in the expression of this protein between the histological intestinal and diffuse types (Lauren classification), as previously reported by Anagnostopoulos et al (34).

Increased expression of p53 protein was observed in the adenocarcinomas (43.1\%) compared with the adjacent normal mucosa (2.4\%). A positive correlation was noted between p53 protein expression and tumor size, histological classification and protein Ki-67 immunoexpression. In a study by Lee et al, similar expression was found in gastric carcinomas, and overexpression of p53 was directly associated with increased age, male gender, larger sized tumors, a higher degree of histological differentiation, PCNA and a more advanced stage of the 
disease (35). These results indicate that, in adenocarcinomas, p53 is unable to correct DNA damage, thus blocking apoptosis and allowing the proliferation of cells with DNA damage. On the other hand, increased expression of Bcl-x helps to inhibit apoptosis, triggering the uncontrolled proliferation of tumor cells.

Sot et al demonstrated that there is high affinity between the p53, Bcl-xl and Bak proteins. When there is an equal concentration of pro- and anti-apoptotic proteins, or with the highest concentration of the latter, p53 preferentially binds to $\mathrm{Bcl}-\mathrm{xl}$, inhibiting its apoptotic effect. If there are too many p53 molecules, the interaction with Bak occurs a second time, activating these proteins and promoting their oligomerization with the anti-apoptotic proteins (36).

Tumor growth is determined by the balance between proliferation and the apoptisis of tumor cells. The measurement of proliferative activity using immunohistochemistry is carried out using antibodies against antigens associated with proliferation, such as Ki-67 and PCNA. The Ki-67 protein is considered to be an important prognostic factor in malignant tumors. Patients with tumors with high proliferative activity have a worse prognosis than those with low activity (37). In this study, increased cell proliferation in tumor tissue compared to adjacent normal mucosa was also observed. An association was found between the rate of cell proliferation measured by $\mathrm{Ki}-67$ in intestinal type adenocarcinomas. Oshima et al observed higher expression of $\mathrm{Ki}-67$ in intestinal type compared with diffuse type adenocarcinomas (38). In another study by Oshima et al, which studied the rate of cell proliferation (determined by $\mathrm{Ki}-67$ ) in gastric and colon cancer, a wide variation in the percentage and intensity of Ki-67 expression was noted. This was higher in gastric carcinomas (39). An increase in the expression of the Ki-67 protein in adenocarcinomas compared with intestinal metaplasia was also observed. In this study, there was no correlation between the expression of the $\mathrm{Bcl}-2$ protein family and patient prognosis.

In conclusion, our results suggest that the expression of $\mathrm{Bcl}-2$ family proteins is involved in gastric carcinogenesis, likely through an inefficient regulation of apoptosis due to overexpression of $\mathrm{Bcl}-\mathrm{x}$ and reduced expression of the proapoptotic proteins Bak and Bad. The association of these findings with the protein overexpression of p53 shows the ineffectiveness of p53 in controlling the proliferation of cells with DNA damage. These results, in association with the overexpression of Ki-67, may elucidate the imbalance between cell proliferation and apoptosis in tumor cells. The difference in Bax and Bad immunohistochemical expression between intestinal and diffuse adenocarcinomas shows that different mechanisms of carcinogenesis are potentially involved. In this study, the expression of these proteins did not appear to influence patient prognosis.

\section{Acknowledgements}

This study was supported by the CAPES (Coordenação de Aperfeiçoamento de Pessoal de Nível Superior) Scholarship no. 45779 and the FAPESP (Funcação de Amparo à Pesquisa do Estado de São Paulo) 'Apoptose em tumores' project nos. 2004/09932-4 and 06/54187-0.

\section{References}

1. Magalhães LP, Oshima CT, Souza LG, Lima JM, Carvalho L and Forones NM: Weight: educational achievement, basic sanitation, alcoholism, smoking and eating habit in patients with gastric cancer. Arq Gastroenterol 45: 111-116, 2008.

2. Lauren P: The two histological main types of gastric carcinoma: diffuse and so-called intestinal-type carcinoma. An attempt at histo-clinical classification. Acta Pathol Microbiol Scand 64: 31-49, 1965

3. Ladeira M, Salvador D and Rodriguez M: Biopatologia do helicobacter pylori. Journal Brasileiro de Patologia e Medicina Laboratorial 39: 335-342, 2003.

4. Zhang C, Yamada N, Wu WL, Wen M, Matsuhisa $\mathrm{T}$ and Matsukura N: Helicobacter pylori infection, glandular atrophy and intestinal metaplasia in superficial gastritis, gastric erosion, erosive gastritis, gastric ulcer and early gastric cancer. World J Gastroenterol 11: 791-796, 2005.

5. Correa P: Human gastric carcinogenesis: a multistep and multifactorial process - First American Cancer Society Award Lecture on Cancer Epidemiology and Prevention. Cancer Res 52: 6735-6740, 1992.

6. Hamilton SR and LA Aaltonen (eds): World Health Organization Classification of Tumors. Pathology and Genetics of Tumors of the Digestive System. IARC Press, Lyon, pp1429-1433, 2003.

7. Hengartner M: The biochemistry of apoptosis. Nature 407: 770-776, 2000.

8. Saraste A and Pulkki K: Morphologic and biochemical hallmarks of apoptosis. Cardiovasc Res 45: 528-537, 2000.

9. Reed JC: Dysregulation of apoptosis in cancer. J Clin Oncol 17: 2941-2953, 1999.

10. Reed JC: Bcl-2 family proteins. Oncogene 17: 3225-3236, 1998.

11. Bratton SB, MacFarlane M, Cain K and Cohen GM: Protein complexes activate distinct caspase cascades in death receptor and stress-induced apoptosis. Exp Cell Res 256: 27-33, 2000.

12. Denault JB and Salvesen GS: Caspases: keys in the ignition of cell death. Chem Rev 102: 4489-4500, 2002.

13. Coultas L and Strasser A: The role of the Bcl-2 protein family in cancer. Semin Cancer Biol 13: 115-123, 2003.

14. Cory S and Adams JM: The Bcl2 family: regulators of the cellular life-or- death switch. Nat Rev Cancer 2: 647-656, 2002.

15. Borner C: The Bcl-2 protein family: sensors and checkpoints for life-or-death decisions. Mol Immunol 39: 615-647, 2003.

16. Susin S, Lorenzo H, Zamzami N, et al: Molecular characterization of mitochondrial apoptosis-inducing factor. Nature 397: 441-446, 1999.

17. Koshida Y, Saegusa M and Okayasu I: Apoptosis, cell proliferation and expression of $\mathrm{Bcl}-2$ and $\mathrm{Bax}$ in gastric carcinomas: immunohistochemical and clinicopathological study. Br J Cancer 75: 367-373, 1997.

18. Bir F, Calli-Demirkan N, Tufan AC, Akbulut $M$ and Satiroglu-Tufan NL: Apoptotic cell death and its relationship to gastric carcinogenesis. World J Gastroenterol 13: 3183-3188, 2007.

19. Reed JC, Miyashita T, Takayama S, Wang HG, Sato T, Krajewski S, Aimé-Sempé C, Bodrug S, Kitada S and Hanada M: BCL-2 family proteins: regulators of cell death involved in the pathogenesis of cancer and resistance to therapy. J Cell Biochem 60: 23-32, 1996.

20. Sobin LH and Wittekind C (eds): International Union against Cancer (UICC) TNM classification of malignant tumours. 5th edition. Wiley-Liss, New York, 1997.

21. Krajewska M, Krawesky S, Epstein J, et al: Immunohistochemical analysis of Bcl-2, bax, bcl-x and mcl-1 expression in prostate cancers. Am J Pathol 148: 1567-1576, 1996.

22. Fernebro E, Dictor M, Bendahl PO, Fernö M and Nilbert M: Evaluation of the tissue microarray technique for immunohistochemical analysis in rectal cancer. Arch Pathol Lab Med 126: 702-705, 2002.

23. Lee DS, Kang SB, Baek JT, Nam SW, Lee KM, Ahn BM, Lee EH, Han SW and Chung IS: Immunohistochemical expression of bcl-2, bcl-xl, bax, p53 proteins in gastric adenoma and adenocarcinoma. Korean J Gastroenterol 45: 394-400, 2005.

24. Forones NM, Carvalho AP, Giannotti-Filho O, Lourenço LG and Oshima CT: Cell proliferation and apoptosis in gastric cancer and intestinal metaplasia. Arq Gastroenterol 42: 30-34, 2005.

25. Müller W, Schneiders A, Hommel G and Gabbert HE: Prognostic value of $\mathrm{Bcl}-2$ expression in gastric cancer. Anticancer Res 18 : 4699-4704, 1998. 
26. Krajewsky S, Krajewska M, ShabaikA, et al:Immunohistochemical analysis of in vivo patterns of Bcl-x expression. Cancer Res 54: 5501-5507, 1994.

27. Krajewska M, Fenoglio-Preiser C, Krajewsky S, et al: Immunohistochemical analysis of Bcl-2 family protein in adenocarcinoma of the stomach. Am J Pathol 49: 1449-1457, 1996.

28. Vairo G, Innes KM and Adams JM: Bcl-2 has a cell cycle inhibitory function separable from its enhancement of cell survival. Oncogene 13: 1511-1519, 1996.

29. Schmitt E, Beauchemin M and Bertand R: Nuclear colocalization and interation between bcl-xL and cdk1 (cde2) during G2/M cell-cycle checkpoint. Oncogene 26: 5851-5865, 2007.

30. Holinger EP, Chittenden T and Lutz RJ: Bak BH3 peptides antagonize $\mathrm{Bcl}-\mathrm{xl}$ function and induce apoptosis through cytochrome c-independent activation of caspases. J Biol Chem 274: 13298-13304, 1999.

31. Hinds MG, Smits C, Fredericks-Short R, Risk JM, Bailey M, Huang DC and Day CL: Bim, Bad and Bmf: intrinsically unstructured $\mathrm{BH} 3$-only proteins that undergo a localized conformational change upon binding to prosurvival $\mathrm{Bcl}-2$ targets. Cell Death Differ 14: 128-136, 2007.

32. Krajewska M, Moss SF, Krajewski S, Song K, Holt PR and Reed JC: Elevated expression of Bcl-X and reduced Bak in primary colorectal adenocarcinomas. Cancer Res 56: 2422-2427, 1996.
33. Estrov Z, Thall PF, Talpaz M, et al: Caspase 2 and caspase-3 protein levels as predictors of survival in acute myelogenous leukemia. Blood 92: 3090-3097, 1998.

34. Anagnostopoulos GK, Stefanou D, Arkoumani E, et al: Bax and $\mathrm{Bcl}-2$ protein expression in gastric precancerous lesions: immunohistochemical study. J Gastroenterol Hepatol 20: 1674-1678, 2005 .

35. Lee KE, Lee HJ, Kim YH, et al: Prognostic significance of p53, nm23, PCNA and c-erbB-2 in gastric cancer. Jpn J Clin Oncol 33: 173-179, 2003.

36. Sot B, Freund SM and Fersht AR: Comparative biophysical characterization of p53 with the pro-apoptotic BAK and the antiapoptotic BCL-xl. J Biol Chem 282: 29193-29200, 2007.

37. Kodera Y, Yamamura Y, Shimizu Y, et al: The number of metastatic lymph nodes: a promising prognostic determinant for gastric carcinoma in the latest edition of the TNM classification. J Am Coll Surg 187: 597-603, 1998.

38. Oshima FTC: Helicobacter pylori and expression of AgNORs, $\mathrm{Ki}-67, \mathrm{c}-\mathrm{erbB}-2$ and $\mathrm{p} 53$ in gastric adenocarcinoma (PhD thesis). Universidade Federal de São Paulo, Escola Paulista de Medicina, São Paulo, 1999.

39. Oshima CT, Iriya K and Forones NM: Ki-67 as a prognostic marker in colorectal cancer but not in gastric cancer. Neoplasma 52: 420-424, 2005. 